\title{
Human Papillomavirus Prevalence, Viral Load and Cervical Intraepithelial Neoplasia in HIV-Infected Women
}

\author{
José E. Levi, Maria C.S. Fink, Cynthia L.M. Canto, \\ Nadily Carretiero, Regina Matsubara, Iara Linhares, \\ Gérson B. das Dores, Adauto Castelo, Aluísio Segurado, \\ David E. Uip and José Eluf Neto
}

\begin{abstract}
HIV-infected women from São Paulo city were enrolled in a cross-sectional study on Human Papillomavirus (HPV) and cervical intraepithelial neoplasia (CIN) prevalence and their association with laboratory markers of AIDS, namely $\mathrm{HIV}$ viral load and $\mathrm{CD}_{4}^{+}$cell counts. A cervical specimen was collected and submitted to Hybrid Capture, a test for HPV viral load determination. HPV-DNA was detected in 173 of 265 women (64.5\%). Twenty $(7.5 \%)$ women were infected by one or more low-risk viruses, $89(33 \%)$ by one or more high-risk viruses, and 64 (24\%) harbored at least one HPV type from each risk group. Abnormal smears were observed in 19\% of the patients, though there were no invasive carcinomas. Severely immunosuppressed patients $\left(\mathrm{CD}_{4} / \boldsymbol{\mu L}<100\right)$ were at the greatest risk of having a cytological abnormality and a high high-risk HPV viral load.

Key Words: Human Papillomavirus, cervical intraepithelial neoplasia, HIV-infected women, viral load, AIDS.
\end{abstract}

Human Papillomavirus (HPV) is the causative agent of cervical cancer and its precursor disease, known as squamous intraepithelial lesion (SIL). Several studies have reported that these HPV-induced lesions are more common [1] and have a worse outcome in Human Immunodeficiency Virus (HIV) infected women [2]. Therefore, investigating how this virus interacts with HIV disease in co-infected patients is of great importance, even more so in the context of the increasing incidence of AIDS among women in Brazil. The aim of this study was to determine the prevalence of HPV and SIL, and to compare markers of HIV

Received on 15 January 2002; revised 30 April 2002.

Address for correspondence: Dr. José Eduardo Levi. Laboratório de Virologia, Instituto de Medicina Tropical da Universidade de São Paulo. Rua Dr. Enéas de Carvalho Aguiar 470, $2^{\circ}$ andar. CEP 05403-000. Phone ++ $551130622645 \mathrm{Fax}++$ 55113063 2659. E-mail: dudilevi@usp.br

Financial support: This study was sponsored by the Brazilian Ministry of Health, CN/DST-AIDS.

The Brazilian Journal of Infectious Diseases 2002;6(3):129-134 (C) 2002 by The Brazilian Journal of Infectious Diseases and Contexto Publishing. All rights reserved. $1413-8670$ disease, specifically $\mathrm{CD}_{4}$ counts and $\mathrm{HIV}$ viral load in a group of HIV-infected women from São Paulo city.

\section{Materials and Methods}

Patients: Between November 1997 and September 1999, 265 HIV infected women making a routine gynecological visit at the outpatient clinic of the Instituto de Infectologia Emílio Ribas or the Casa da AIDS were invited to participate in the study. Patients were included in the study if they had confirmed HIV infection, were being treated as outpatients and were willing give written, informed consent. This study was approved by the Ethics Committees of both institutions.

Biological samples: During the visit, blood was collected for a $\mathrm{CD}_{4}$ count and HIV viral load determination. In addition, a cervical smear was obtained for cytological analysis and cervicovaginal cells collected with a brush (Digene Cervical Sampler, Digene do Brasil, São Paulo-SP) that was immediately placed on Sample Transport Medium (STM, Digene 
do Brasil, São Paulo-SP) and brought the same day to the virology laboratory of the Instituto de Medicina Tropical.

Cytological analysis: Cervical smears were stained by the Papanicolau method and classified into: Normal, Inflammatory, grade 1 to 3 Cervical Intraepithelial Neoplasia (CIN) and Invasive Carcinoma.

$H I V$ : Plasma was separated within 6 hours after the blood was drawn, and then frozen at $-20^{\circ} \mathrm{C}$. Viral load was determined with an RT-PCR based kit, Amplicor HIV-1 Monitor (version 1.0, Roche Diagnóstica, São Paulo - SP, Brazil). The detection threshold was 400 copies/mL.

$H P V:$ HPV detection and quantitation was assessed by the Hybrid Capture II (HC II) method, a nonisotopic signal amplification technique based on the hybridization of biotinylated RNA probes to the DNA of HPV in the samples. The RNA-DNA hybrids were immobilized in microplate wells by an antibody adsorbed to the well surface. A cocktail of probes for low-risk HPV types (group A, including HPV types 6, $11,42,43$, and 44) and high-risk types (group B, including HPV 16, 18, 31, 33, 35, 39, 45, 51, 53, 56, 58,59 , and 68) allowed for the discrimination of the HPV group present in the sample, though the characterization of individual types was not attempted. Viral load was estimated by comparison with the signal generated by $1 \mathrm{pg} / \mathrm{mL}$ ofHPV. Samples giving a signal greater than 1 were considered "positive" for the respective HPV group.

The samples were denatured upon arrival at the lab and an aliquot was removed for DNA precipitation for other molecular analyses. Denatured samples were then transported frozen to Digene do Brasil, where HC II analysis was completed.

\section{Results}

Two hundred and sixty-five HIV-infected women were investigated. They were predominantly young (range $=18-67$ years; mean age $=32.4 \pm 7.7$ years; median $=32$ years), with $\mathrm{CD}_{4}$ counts ranging from 8 to 978 cells $/ \mu \mathrm{L}($ mean $=296.84 \pm 174.72$ cells $/ \mu \mathrm{L}$; median $=285$ cells $/ \mu \mathrm{L})$ and HIV viral loads ranging from undetectable $(<400$ copies $/ \mathrm{mL})$ to above the superior limit of the detection method $(>750,000$ copies/mL) (mean $62,235 \pm 145,884$ copies/mL; median $=5,764$ copies $/ \mathrm{mL}$ ). For the purpose of statistical analysis, samples in which HIV RNA was undetectable were arbitrarily ascribed as 100 copies/ $\mathrm{mL}$ and those $>750,000$ copies $/ \mathrm{mL}$ were assigned $1,000,000$ copies $/ \mathrm{mL}$. Among the 265 women, HPV DNA was present in 173 (64.5\%). Twenty (7.5\%) women were infected by one or more low-risk viruses, $89(33 \%)$ women by one or more high-risk viruses, and $64(24 \%)$ women harbored at least one HPV type from each risk group. Ten cytological smears were not analyzed due to the absence of cervical cells (2), hemorrhage (2), broken slide (2) and lost slide (4). Of the remaining 255, 48 presented alterations compatible with CIN (19\%). There was no case of invasive carcinoma. The majority $(80 \%, \mathrm{~N}=210)$ of the patients were under some kind of anti-retroviral treatment regime (Table 1).

Age: Age was not significantly different among women with positive versus negative HC II results. The prevalence of HPV infection and CIN in the various age groups is depicted in Figure 1. Younger women (18-25 years) tended to have a higher prevalence of $\mathrm{CIN}$ and of low and high-risk HPV types; $\mathrm{CD}_{4}$ counts and HIV RNA levels did not differ among the age groups (data not shown).

CD4: $\mathrm{A} \mathrm{CD}_{4}$ count lower than 100 cells $/ \mu \mathrm{L}$ was highly predictive of concurrent infection with one or more highrisk HPVs. Seventy-eight percent of the patients within this lower range of $\mathrm{CD}_{4}$ counts were positive for highrisk HPVs by HC II test, whereas about $94 \%$ of probeB-negative individuals had $\mathrm{CD}_{4}$ counts higher than 100 cells $/ \mu \mathrm{L}$ (Table 2 ). Extremely immunosuppressed women $(<100$ cells $/ \mu \mathrm{L})$ had a greater chance of bearing a dysplastic smear in comparison to those with 
Table 1. Demographic, clinical and laboratory data of the women enrolled in the study, according to their Hybrid Capture results

\begin{tabular}{|c|c|c|c|c|c|c|}
\hline $\begin{array}{l}\text { Hybrid Capture } \\
\qquad(N=265)\end{array}$ & $\begin{array}{l}\text { Age } \\
\text { Years* }\end{array}$ & $\begin{array}{l}\text { HIVViral } \\
\text { Load* } \\
\text { Copies } / m L\end{array}$ & $\mathrm{CD} 4 / \mu \mathrm{L}^{*}$ & $\begin{array}{c}\text { HPV Viral } \\
\text { Load* } \\
\text { (RLU/PCAor } \\
\text { PCB) }\end{array}$ & CIN Cytology & $\begin{array}{c}\text { On antiretroviral } \\
\text { therapy }\end{array}$ \\
\hline $\begin{array}{l}\text { Negative } \\
\qquad(34 \% ; N=92)\end{array}$ & $\begin{array}{c}34 \\
\pm 7.2\end{array}$ & $\begin{array}{c}38,425 \\
\pm 130,987\end{array}$ & $\begin{array}{r}364.7 \\
\pm 183.8\end{array}$ & & $5(5 \%)$ & $67(73 \%)$ \\
\hline $\begin{array}{l}\text { Positive low risk } \\
(7.5 \% ; \mathrm{N}=20)\end{array}$ & $\begin{array}{c}32 \\
\pm 7.7\end{array}$ & $\begin{array}{l}65,206 \\
\pm 90,676\end{array}$ & $\begin{array}{c}237.7 \\
\pm 114.4\end{array}$ & $\begin{array}{c}203.28 \\
\pm 400.17\end{array}$ & $5(2 \%)$ & $13(65 \%)$ \\
\hline $\begin{array}{l}\text { Positive high risk } \\
(33 \% ; \mathrm{N}=89)\end{array}$ & $\begin{array}{c}33 \\
\pm 8.3\end{array}$ & $\begin{array}{c}53,735 \\
\pm 112,577\end{array}$ & $\begin{aligned} & 288 \\
\pm & 161.9\end{aligned}$ & $\begin{array}{c}348.29 \\
\pm 570.58\end{array}$ & $19(22 \%)$ & $74(83 \%)$ \\
\hline $\begin{array}{l}\text { Positive low and } \\
\text { high risk } \\
(24 \% ; \mathrm{N}=64)\end{array}$ & $\begin{array}{c}29 \\
\pm 6.2\end{array}$ & $\begin{array}{c}106,012 \\
\pm 204,466\end{array}$ & $\begin{aligned} & 229 \\
\pm & 161.5\end{aligned}$ & $\begin{array}{c}263.55 \\
\pm 495.71 \\
805.93 \\
\pm 884.95\end{array}$ & $19(30 \%)$ & $56(87.5 \%)$ \\
\hline
\end{tabular}

* Numbers represent mean \pm 1 standard deviation.

Table 2. HIV, HPV and cytology according to the CD4/ $\mu \mathrm{L}$ count

\begin{tabular}{lcccc}
\hline CD4/ $\boldsymbol{\mu L}$ & $\begin{array}{c}\text { Prevalence of CIN } \\
(\mathbf{1 - 3}) \text { on Pap Smear }\end{array}$ & $\begin{array}{c}\text { HIV Viral Load } \\
\text { (mean, copies/mL) }\end{array}$ & $\begin{array}{c}\text { HPV Viral Load } \\
\text { RLU/PCA (median) }\end{array}$ & $\begin{array}{c}\text { HPV Viral Load } \\
\text { RLU/PCB (median) }\end{array}$ \\
\hline$<100 . \mathrm{N}=32$ & $37.50 \%$ & 106,512 & 14.11 & 324.96 \\
$101-200 . \mathrm{N}=52$ & $27.00 \%$ & 100,748 & 462.25 & 178.06 \\
$201-300 . \mathrm{N}=58$ & $8.70 \%$ & 54,356 & 5.39 & 220.21 \\
$301-400 . \mathrm{N}=59$ & $15.25 \%$ & 37,008 & 8.07 & 204.32 \\
$>400 \mathrm{~N}=62$ & $13.00 \%$ & 42,079 & 17.63 & 15.01 \\
\hline
\end{tabular}

Table 3. HPV, CD4 and HIV viral load according to cytological results

\begin{tabular}{lcc}
\hline & \multicolumn{2}{c}{ Cytology } \\
\cline { 2 - 3 } & Normal/Inflammatory N=207 & CIN 1-3 N=48 \\
\hline CD4/ $\mu$ L (mean + SD) & $310.4+173.5$ & $233.2+171.8$ \\
HIV Viral Load & $58,777+150,829$ & $87,667+137,316$ \\
$\quad($ mean + SD) & & \\
AGE (mean + SD) & $33+7.6$ & $31+7.8$ \\
POSITIVE A & $7.25 \%$ & $10.42 \%$ \\
POSITIVE B & $31.40 \%$ & $39.60 \%$ \\
POSITIVE A and B & $20.30 \%$ & $39.60 \%$ \\
HPV Viral Load RLU/PCB & $428.6+684.65$ & $1,194.53+888.18$ \\
$\quad($ Mean + SD) & & \\
\hline
\end{tabular}


Figure 1. Prevalence of HPV group A, B and both and CIN according to age group

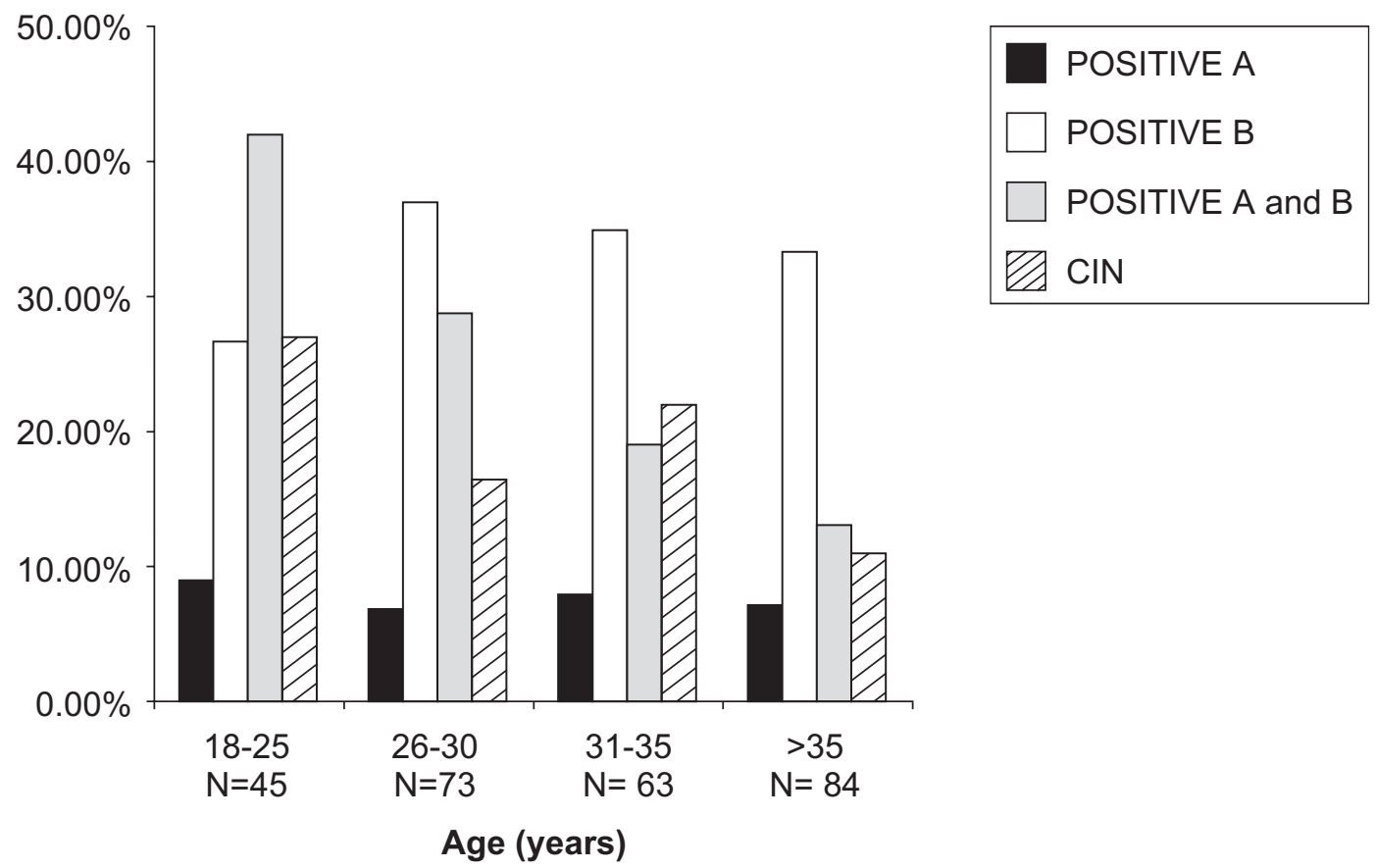

Figure 2. Low-risk and high-risk HPV positivity and prevalence of CIN according to HIV-1 viral load

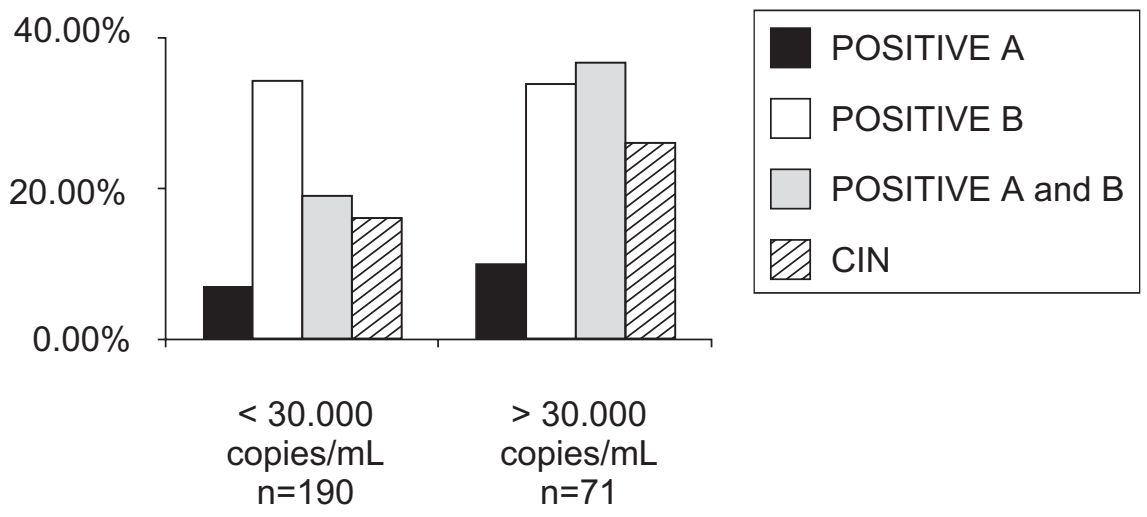


$\mathrm{CD}_{4}>100$ cells $/ \mu \mathrm{L}(\mathrm{p}=0.004 ; \mathrm{OR}=3.11)$ and of being infected by a high-risk group HPV $(\mathrm{p}=0.01 ; \mathrm{OR}=$ 2.93).

HIV Viral Load: As expected, HIV viral load was less predictive than $\mathrm{CD}_{4}$ cell counts for both high-risk HPV detection and altered cytology. Individuals with a viral load higher than 30,000 copies/mL had a prevalence of high-risk HPVs similar to those harboring less than 30,000 copies/mL (Figure 2), but the occurrence of concomitant low and high-risk HPVs and of CIN was higher in patients with HIV viral loads above 30,000 copies $/ \mathrm{mL}$.

Squamous Intraepithelial Lesions (SIL): The overall prevalence of altered cytological smears was 19\% (48 altered smears among 255 readable slides). These altered cytologies can be further divided into high-grade SILs (HSIL), corresponding to CIN2 (13 patients; 5\%) and CIN3 (5 patients; $2 \%$ ) and low-grade SILs (LSIL), corresponding to CIN 1 (30 patients; 12\%). Five patients with prevalent SILs had a negative HC II test and five were positive for the low-risk probe only. The sensitivity of the high-risk probe for a concomitant CIN diagnosis was $80 \%$ (38/48). The specificity was $48 \%$ (99/207), due to the high prevalence of HPV in this population. The positive predictive value of the HCII test for an altered cytology was 26\% (38/146) while the negative predictive value was very high at 91\%(99/ 109). In summary, as illustrated in Table 3 , patients with a CIN diagnosis based on cytology were more severely immunosuppressed and had higher HIV and HPV viral loads, in comparison with those with normal/ inflammatory Pap smears. The low prevalence of each CIN grade precluded an individual analysis; instead we preferred to analyze them all together.

\section{Discussion}

Human Papillomaviruses were frequent in this population of HIV-infected women. In fact, the observed prevalence of $66 \%$ is comparable to the $63.2 \%$ found by Massad and cols.[3] who made a
PCR analysis of cervicovaginal washes from 1,517 HIV-infected North-American women and to the 56\% found in HIV-infected Senegalese commercial sex workers [4]. In another study done on $141 \mathrm{HIV}$ infected women from Santos - Brazil, HPV DNA was detected by PCR in $80.8 \%$ of the patients [5]. This high prevalence of HPV is not unexpected since the majority of these women were infected by sexual transmission, a common route for both HIV and HPV acquisition. Similarly to what is found in HIVseronegative populations, the high-risk group HPVs were more prevalent than those of the low-risk group and women from 18-25 years of age had the highest rate of infection (Figure 1).

Cervical abnormalities, determined by cytological analysis, were found in 48 women (19\%) but only 5 had high-grade lesions ( $2 \%, \mathrm{CIN} 3)$ and no invasive carcinomas were observed. A strong correlation was found between immunosuppression, as measured by $\mathrm{CD}_{4}$ counts, and prevalent SILs as $37.5 \%$ of the patients with $\mathrm{CD}_{4} / \mu \mathrm{L}<100$ had an important cytological alteration compared to $13 \%$ of the patients with $\mathrm{CD}_{4} /$ $\mu \mathrm{L}>400$. Several authors have reported prevalences of $20-40 \%$ SIL in HIV seropositive women, varying accordingly to the population, immune status and antiretroviral therapy. Immunosuppression seems to have an influence both on HPV prevalence and viral load, as depicted in Table 2. Median HPV viral loads decreased with increasing $\mathrm{CD}_{4}$ counts; this was more evident in patients with over 400 cells $/ \mu \mathrm{L}$. This data suggests that HIV-mediated immunosuppression allows an increase in HPV replication that could enhance the detection rate, which would explain the higher HPV prevalence observed in these groups.

Five women with altered smears were negative in the HCII test, which could be explained by lesions caused by HPV types not detected by the HCII method or by an HPV viral load below the detection threshold. Alternatively, it could be due to misclassification of the Pap smear. Another five women with cytological evidence of CIN were reactive for the low risk probe only, a finding that is quite unusual in immunocompetent women, though it has been described in HIV-infected patients [6]. 
In conclusion this study shows that the prevalence of HPV in HIV-infected women in São Paulo is very high, accompanied by an elevated rate of squamous intraepithelial lesions, which seem to be more common among severely immunosuppressed patients. Palefsky et al. [7] found evidence that the high rate of HPV in HIV-infected women is a result of reactivation of cumulative latent viruses rather than recent acquisition, and Sun et al. [8], who repeatedly tested HIV-infected women for HPV by PCR, observed a high rate of persistent HPV infection, a known risk factor for the development of SIL. Our results suggest that a close surveillance for cervical malignancies is warranted in HIVinfected women. The Hybrid Capture test could play an important role since it was found to be predictive of existing SILs in this and other studies [9]. Specifically, we think that this test would be useful in assuring the inexistence of HPV-induced lesions since it had a significant negative predictive value. The outcome of the SILs found in this population can only be assessed by a longitudinal study, in which the influence of the course of HIV disease must be controlled. At present it is not known if the introduction of HAART will have a favorable effect on SILs. Possibly, by allowing partial restoration of immune functions, patients will be able to clear HPV infection and SILs may regress, as observed by Heard et al. [10] after investigating HIV infected women on HAART for 5 months. On the other hand, due to the increase in patient survival, SIL lesions will have more time to progress and, if this is the case, we would expect an increase in the incidence of "in situ" and invasive carcinomas on HIV patients receiving HAART. A direct interaction between HPV and HIV is not supported by our data, since there was no clear correlation among the viral loads.
2. Kuhn L., Sun X.-W., Wright T.C. HIV infection and female lower genital tract malignancy. Curr Opin Obstet Gynecol 1999; 11:35-9.

3. Massad L.S., Riester K.A., Anastos K.M., et al. Prevalence and predictors of squamous cell abnormalities in Papanicolau smears from women infected with HIV-1. J AIDS 1999;21:33-41.

4. Langley C.L., Benga-De E., Critchlow C.W., et al. HIV-1, HIV-2, human papillomavirus infection and cervical neoplasia in high-risk African women. AIDS 1996; 10:413-7.

5. Goncalves M.A., Massad E., Burattini M.N., Villa L.L. Relationship between human papillomavirus (HPV) genotyping and genital neoplasia in HIV-positive patients of Santos City, São Paulo, Brazil. Int J STD AIDS 1999; 10:803-7.

6. Cappielo G., Garbuglia A.R., Salvi R. et al., HIV infection increases the risk of squamous intra-epithelial lesions in women with HPV infection: an analysis of HPV genotypes. Int J Cancer 1997;72:982-6.

7. Palefsky J.M., Minkoff H., Kalish L.A., et al. Cervicovaginal human papillomavirus infection in human immunodeficiency virus-1 (HIV)-positive and high-risk HIV-negative women. J Natl Cancer Inst 1999;91:226-36.

8. Sun X.-W.., Kuhn L., Ellerbrock T.V., et al. Human papillomavirus infection in women infected with the human immunodeficiency virus. N Engl J Med 1997;337:1343-9.

9. Petry K.U., Böhmer G., Iftner T., et al. Human papillomavirus testing in primary screening for cervical cancer of human immunodeficiency virus-infected women, 1990-1998. Gynecol Oncol 1999;75,427-31.

10. Heard I., Schmitz V., Costagliola D., et al. Early regression of cervical lesions in HIV-seropositive women receiving highly active antiretroviral therapy. AIDS 1998; $12: 1459-64$.

\section{References}

1. Ellerbrock T.V., Chiasson M.A., Bush T.J., et al. Incidence of cervical squamous intraepithelial lesions in HIVinfected women. JAMA 2000;283:1031-7. 